Volume 18, No 4 International Journal of Radiation Research, October 2020

\title{
Estimating and comparing the radiation cancer risk from cone-beam computed tomography and panoramic radiography in pediatric and adult patients
}

\author{
H. Zamani' ${ }^{1}$ F. Falahati ${ }^{1}$, R. Omidi ${ }^{1}$, R. Abedi-Firouzjah ${ }^{2}$, M.H. Zare ${ }^{1}$, \\ F. Momeni*3
}

${ }^{1}$ Department of Medical Physics, Faculty of Medicine, Shahid Sadoughi University of Medical Sciences, Yazd, Iran
2Cellular and Molecular Research Center, Yasuj University of Medical Sciences, Yasuj, Iran
${ }^{3}$ Medical Physics and Medical Engineering Department, School of Medicine, Shiraz University of Medical Sciences, Shiraz, Iran

\section{- Original article}

\section{*Corresponding authors: \\ Dr. Mohammad Hosein Zare and \\ Dr. Farideh Momeni, \\ E-mail: \\ mhzare2009@gmail.com momenifarideh777@gmail.com}

Revised: June 2020

Accepted: July 2020

Int. J. Radiat. Res., October 2020; 18(4): 885-893

DOI: 10.18869 /acadpub.ijrr.18.4.885

\section{ABSTRACT}

Background: This study aimed to estimate and compare the absorbed dose, lifetime cancer risk and mortalities due to cone-beam computed tomography (CBCT) and panoramic examinations on patients. Materials and Methods: The exposure factors were applied to 332 patients in two age groups (6-10, and $>18$-year-old). The dose-area product (DAP) values were measured for CBCT and panoramic radiographies. Organ absorbed doses and effective doses were calculated based on the collected parameters applying PCXMC software. The risk of exposure-induced death (REID) and cancer risks were estimated by BEIR VII phase 2 model at different age groups and genders for the two dental radiography modalities. Results: Salivary glands was the largest contribution of the organ absorbed dose and effective dose in both CBCT and panoramic radiographies. The mean ( $\pm S D)$ REID values (per ten million) in CBCT were obtained at $35.6 \pm 5.2$ for females and $29.01 \pm 1.8$ for males, in the pediatric group, and were 31.1 \pm 2.2 for females and $25.71 \pm 2.02$ for males in the adult group for all cancers. In addition, these values for panoramic radiography were $10.2 \pm 1.2$ and $6.61 \pm 1.2$ for women and men, respectively, in the pediatric group, and were $5.3 \pm 1.06$ and $3.01 \pm 1.12$ in the adult group. The mean REID values were higher significantly in CBCT compared to panoramic, and also in the pediatric than adult groups $(p<0.05)$. Conclusion: CBCT had a significantly higher level of radiation risks compared to panoramic radiography. Therefore, clinicians should request CBCT examinations by considering their determents and benefits.

Keywords: Cone-beam computed tomography, panoramic radiography, effective dose, cancer risk, dose-area product.

\section{INTRODUCTION}

In recent years, cone-beam computed tomography (CBCT) devices have increased in dentistry departments to optimize the diagnoses and treatments (1). As compared with traditional radiographs such as panoramic, CBCT supports a wide range of applicability including 3D image quality and has accurate diagnosis of skeletal asymmetry, easier location of impacted teeth, improved surgical planning, and increased detection of pathologies placing (2-4). Its benefits have been widely reported, however, CBCT scans have poor soft-tissue contrast and artifacts, and also expose the patient to biologic risks of ionizing radiation (5-7).

The amount of patient exposure dose in diagnostic dental CBCT examination remains an important issue. Several studies have demonstrated that CBCT's have higher radiation 
dose compared to intra-oral or extra-oral conventional methods of X-ray. For instance, Grünheid et al. (8) have indicated that CBCT delivers a higher effective dose to the patient than a typical panoramic radiograph by $3.22-$ 6.24 times. In another study, Li et al. (7) reported that the effective dose for panoramic radiographs was about $22 \mu \mathrm{Sv}$ and for CBCT examination ranged from 61-134 $\mu \mathrm{Sv}$. Nevertheless, all are considered low doses compared to all natural environmental radiation received for life.

Although radiation doses to the patients undergoing the panoramic radiographs and CBCT scans are usually low, the number of examinations has been increased (9-11). Therefore, dentists' awareness of the risk of cancer from these tests is important for making the appropriate decisions.

Several studies have reported radiation doses from dental radiographies. For example, in a study, Aps etal. (12) expressed the thyroid gland's radiation dose from radiographies taken in dento-alveolar trauma cases in pediatric patients using PCXMC (personal computer X-ray Monte Carlo calculations) software. In another study, Souza et al. (13) obtained the absorbed dose of the thyroid gland during intra-oral dental examinations using male and female phantoms. Also, they estimated the lifetime cancer incidence attributable to dental examinations for adults in both genders.

The effective dose is a suitable dose index to assess the patient radiation risk from ionization radiation, however, it does not express its value in terms of gender and age, while these criteria will account in REID (risk of exposure-induced cancer death) values (14).

Following our investigation, the previous studies have reported the REID values for children or/and adults in panoramic radiography $(10,15,16)$, or only for $\operatorname{CBCT}(15,17)$. In the present study, we obtained the dose-area product (DAP), organ doses, effective dose, cancer risk and REID values for two different patient groups in CBCT and panoramic radiographies. Briefly, the distigushing feature of the present study was to (a) calculate organ doses and effective doses resulting from the CBCT and panoramic radiographies, and (b) estimate REID values and cancer risk for the patients in pediatric and adults performed in both male and female groups.

\section{MATERIALS AND METHODS}

\section{Data collection}

In this study, 332 patients have participated in two different age groups. The study was done following National Research Ethics Board approval with the registration number of "IR.SSU.MEDICINE.REC.1398.118" at "15.04.1398". The patients' groups were set as 6-10 and over 18 years old. Three CBCT and 7 digital panoramic machines were assessed in the radiology departments. The information and technical specifications of the studied systems were summarized in table 1. Exposure factors for CBCT and panoramic methods, including tube-current exposure-time product (mAs) and tube voltage $(\mathrm{kVp})$ were determined for the two

Table 1. Information and technical specifications of the equipment evaluated.

\begin{tabular}{|c|c|c|c|c|c|c|}
\hline Equipment & Model & Manufacture- country & Year of manufacture & Total filtration mm (Al) & kVp max & Type \\
\hline \multirow{4}{*}{ Panoramic } & PM2002CC & Planmeca-Finland & 2010 & 2.5 & 80 & DR \\
\cline { 2 - 7 } & Promax 3D & Planmeca-Finland & 2018 & 2.5 & 84 & DR \\
\cline { 2 - 7 } & Promax 3D & Planmeca-Finland & 2018 & 2.5 & 84 & DR \\
\cline { 2 - 7 } & Promax 3D & Planmeca-Finland & 2019 & 2.5 & 84 & DR \\
\cline { 2 - 7 } & Ray Scan $\alpha-S C$ & Toshiba-Japan & 2014 & 2.6 & 100 & DR \\
\cline { 2 - 7 } & Soredex & Soredex-Finland & 2011 & 2.7 & 85 & DR \\
\cline { 2 - 7 } & Promax XC & Planmeca-Finland & 2012 & 2.5 & 80 & DR \\
\hline \multirow{3}{*}{ CBCT } & Promax 3D & Finland & 2009 & 2.5 & 84 & DR \\
\cline { 2 - 7 } & CANON & France & 2019 & 2.5 & 80 & DR \\
\cline { 2 - 7 } & HDX WILL DENTRI $\alpha$ & Korea & 2017 & & 90 & DR \\
\hline
\end{tabular}


age groups. Patients' anatomical data including weight, height, age, and body mass index (BMI, $\mathrm{kg} / \mathrm{m}^{2}$ ) were measured.

DAP values were measured by a DAP-meter (Diamentor M4-KDK, PTW, Freiburg, Germany) consisting of a large area ionization chamber mounted directly in front of the exit portion of the X-ray tube. The measurements of DAP were performed in the absence of the patients, while the exposure factors related to the patients were applied for every dental radiography at different $\mathrm{X}$-ray machines (16).

\section{PCXMC simulation}

The Monte Carlo code named PCXMC 2.0 Ration (STUK, Helsinki, Finland) was used to calculate the organ doses and effective doses in medical X-ray examinations. For CBCT, the patient data (age, gender, height, and weight of the simulation), beam parameters, and irradiation geometry were defined and modeled for all teeth in all age groups. The parameters for the PCXMC software include 360-degree rotation, the coordinate of the location, focus-skin distance, the size of the radiation field, number of photon beams, and maximum energy. This software can work with arbitrarily high photon numbers. Indeed, the number of histories was set to one hundred thousand for all examinations to achieve less than $0.1 \%$ statistical uncertainty in the simulation results.

The geometry of projections in panoramic radiography could not be completely simulated all at once in PCXMC software, therefore, it was simulated by splitting the scan into eighteen sections of the left to the right ear. The parameters for the PCXMC including the size of the radiation field, the coordinates of the location and beam angle on the patient, focus-reference point distance, the number of simulated photons, and maximum energy were defined for each section.

\section{Calculation of organ doses and effective doses}

The effective dose is calculated by the equation: $E=\Sigma W_{T} H_{T}$, where $W_{T}$ is the tissue weighting factor representing the relative contribution of that organ or tissue to the overall risk, and $\mathrm{H}_{\mathrm{T}}$ is equivalent dose $(14,18)$. Therefore, to achieve the effective dose and cancer risk from radiology tests, it is necessary to obtain organs' absorbed doses. The organ doses and effective doses were calculated by the PCXMC for panoramic and CBCT dental radiographies. For each dental radiography, the measured DAP, $\mathrm{kVp}$, and total filtration were entered into the program to calculate the organ doses. The effective doses were calculated in 29 organs and tissues based on weighting factors of ICRP-103 (18) and ICRP-60 dosimetry recommendations (14).

\section{Calculation of induced cancer risks and mortalities}

The lifetime attributable risk of cancer incidence and mortality from the exposure to ionizing radiation was estimated by BEIR VII phase 2 model (19) and PCXMC software. The BEIR VII model was developed to provide an estimate of cancer risk for an exposed individual. These models require expressing the dependence of risk not only on radiation dose but also on sex and age at exposure.

In PCXMC software, lifetime cancer risk mortalities are expressed in terms of REID. In addition, the cancer risks were estimated for the brain, thyroid, all solids, and all cancers for both genders and machines.

\section{Statistical analysis}

The statistically significant results of cancer risk and REID among the age groups, genders, and systems were assessed by one-way ANOVA and Man-Whitney test by SPSS version 19 (SPSS Inc., Chicago, Illinois, US). The level of statistical significance was set at $\mathrm{p}<0.05$.

\section{RESULTS}

\section{Data measurement}

Table 2 represents the patient demographic data in both groups including the average age, weight, height, and BMI examined in this study. The exposure parameters data $(\mathrm{kVp}$ and $\mathrm{mAs})$, and DAP values $\left(\mathrm{mGy} . \mathrm{cm}^{2}\right)$ for panoramic radiography and CBCT are shown in tables 3 and 4 , respectively. 
Table 2. The mean $( \pm S D$ ) values of patient demographic data.

\begin{tabular}{|c|c|c|c|c|}
\hline \multirow{2}{*}{} & \multicolumn{2}{|c|}{ CBCT } & \multicolumn{2}{c|}{ Panoramic } \\
\cline { 2 - 5 } & Pediatric & Adult & Pediatric & Adult \\
\hline Number of patient & 30 & 101 & 60 & 141 \\
\hline Age (year) & $9.3 \pm 1.26$ & $37.8 \pm 12.17$ & $9.17 \pm 1.66$ & $37.95 \pm 10.2$ \\
\hline Weight $(\mathrm{kg})$ & $35.0 \pm 14.0$ & $69.0 \pm 14.0$ & $39.0 \pm 16.0$ & $70.0 \pm 19.0$ \\
\hline Height $(\mathrm{cm})$ & $136.0 \pm 7.0$ & $175.0 \pm 0.0$ & $139.0 \pm 12.0$ & $170.0 \pm 9.0$ \\
\hline BMI $\left(\mathrm{kg} / \mathrm{m}^{2}\right)$ & $19.0 \pm 7.0$ & $22.0 \pm 4.0$ & $20.0 \pm 5.0$ & $24.0 \pm 6.0$ \\
\hline
\end{tabular}

Table 3. The mean $( \pm S D)$ values of $k V p, m A s$, and DAP $\left(m G y . \mathrm{cm}^{2}\right)$ for two age groups in panoramic radiography.

\begin{tabular}{|c|c|c|c|c|c|c|}
\hline \multirow{2}{*}{ Device } & \multicolumn{5}{|c|}{ Age groups } \\
\cline { 2 - 7 } & \multicolumn{3}{|c|}{$\mathbf{6 - 1 0}$ year-old } & $\mathbf{3}$ & \multicolumn{3}{c|}{ 18-year-old } \\
\cline { 2 - 7 } & $\mathbf{k V p}$ & $\mathbf{m A s}$ & $\mathbf{D A P}$ & $\mathbf{k V p}$ & $\mathbf{m A s}$ & DAP \\
\hline 1 & $65.4 \pm 0.96$ & $100.8 \pm 12.0$ & $71.99 \pm 13.0$ & $66.1 \pm 1.0$ & $108.0 \pm 5.7$ & $79.8 \pm 5.3$ \\
\hline 2 & $63.8 \pm 1.47$ & $98.43 \pm 23.4$ & $77.7 \pm 11.83$ & $66.4 \pm 0.82$ & $128.9 \pm 14.0$ & $103.3 \pm 13.0$ \\
\hline 3 & - & - & - & $66.0 \pm 0.0$ & $1.026 \pm 0.0$ & $99.7 \pm 0.0$ \\
\hline 4 & $65.1 \pm 1.79$ & $106.1 \pm 11$ & $83.16 \pm 14.0$ & $69.1 \pm 1.16$ & $142.4 \pm 18.0$ & $126.2 \pm 20.0$ \\
\hline 5 & $68.6 \pm 1.26$ & $79.0 \pm 0.0$ & $50.89 \pm 1.9$ & $71.4 \pm 1.23$ & $133.0 .2 \pm 5.5$ & $93.38 \pm 7.0$ \\
\hline 6 & $57.0 \pm 0.0$ & $86.0 \pm 0$ & $27.0 \pm 0.0$ & $63.0 \pm 0.0$ & $110.0 \pm 0.0$ & $45.1 \pm 0.0$ \\
\hline 7 & $60.0 \pm 0.0$ & $48.0 \pm 0.0$ & $21.6 \pm 0$ & $66.0 \pm 0.0$ & $137.0 \pm 0.0$ & $91.0 \pm 0$ \\
\hline Total & $63.31 \pm 0.9$ & $86.52 \pm 15.4$ & $55.4 \pm 13.5$ & $66.85 \pm 1.2$ & $126.4 \pm 6.17$ & $91.22 \pm 6.47$ \\
\hline
\end{tabular}

Table 4. The mean ( $\pm S D$ ) values of $k V p$, $m A s$, and DAP (mGy.cm2) for two age groups in CBCT radiography.

\begin{tabular}{|c|c|c|c|c|c|c|}
\hline \multirow{3}{*}{ Device } & \multicolumn{6}{|c|}{ Age groups } \\
\cline { 2 - 7 } & \multicolumn{3}{|c|}{$\mathbf{6 - 1 0}$ year-old } & \multicolumn{3}{c|}{$>$ 18-year-old } \\
\cline { 2 - 7 } & $\mathbf{k V p}$ & $\mathbf{m A s}$ & $\mathbf{D A P}$ & $\mathbf{k V p}$ & $\mathbf{m A s}$ & DAP \\
\hline 1 & $80 \pm 0$ & $108 \pm 0$ & $663 \pm 0$ & $84 \pm 0$ & $147 \pm 51.67$ & $805.0 \pm 14.42$ \\
\hline 2 & - & - & - & $80 \pm 0$ & $200 \pm 0$ & $595.5 \pm 0$ \\
\hline 3 & - & - & - & $90 \pm 0$ & $113 \pm 2.49$ & $1430 \pm 12.47$ \\
\hline Total & $80 \pm 0$ & $108 \pm 0$ & $663 \pm 0$ & $84.6 \pm 0$ & $153.3 \pm 18.05$ & $943.8 \pm 8.96$ \\
\hline
\end{tabular}

\section{Calculation of organ absorbed dose and effective dose}

The mean values with standard deviation $( \pm$ SD) of organ absorbed doses and effective doses from the two different devices are listed in table 5 in terms of $\mu \mathrm{Gy}$ and $\mu \mathrm{Sv}$, respectively. The effective dose of CBCT is significantly higher than that of dental panoramic machine. Also in both pediatric and adult groups and systems, the absorbed doses for pediatric subject were significantly higher compared to the adults $(\mathrm{p}<0.05)$.

According to table 5, in CBCT, the largest contribution of the organ absorbed dose was from the salivary glands $(1770 \pm 8.53 \mu \mathrm{Gy}$ for the pediatric and $2950 \pm 299.9 \mu \mathrm{Gy}$ for the adult groups), and the oral mucosa was in second place $(908.41 \pm 11.9 \mu \mathrm{Gy}$ for the pediatric and $1470 \pm 119.5 \mu \mathrm{Gy}$ for the adult groups). For panoramic machine, the mean organ absorbed dose of salivary glands was $281.55 \pm 59.68$ and $318.47 \pm 68.92 \mu \mathrm{Gy}$ for the pediatric and adult patients, respectively, which contribute the highest level. This number for oral mucosa as the second highest organ was $213.26 \pm 56.15$ and $231.6 \pm 67.18 \mu \mathrm{Gy}$ for the pediatric and adult groups, in that order. Thyroid and extrathoracic regions received a higher dose than the other organs in both machines and groups which suggests that the organ absorbed doses are higher in the irradiated and its adjacent area.

The mean effective dose for panoramic radiography was $12.4 \pm 4.13$ and $10.51 \pm 3.04 \mu \mathrm{Sv}$ in pediatric and adult groups, respectively. This number for CBCT was $17.3 \pm 5.17$ and $9.41 \pm 2.94$ $\mu \mathrm{Sv}$ in pediatric and adult age groups, respectively. In almost all examinations, the effective dose decreased significantly with an increase in age (pediatric vs. adult) $(\mathrm{p}<0.05)$. 
Table 5. The mean ( $\pm S D$ ) values of organ absorbed dose and effective dose of panoramic and $C B C T$ machines for pediatric and adult groups.

\begin{tabular}{|c|c|c|c|c|}
\hline \multirow{2}{*}{ Organs } & \multicolumn{2}{|c|}{ Absorbed dose ( $\mu \mathrm{Gy}$ ) from panoramic } & \multicolumn{2}{|c|}{ Absorbed dose ( $\mu \mathrm{Gy}$ ) from CBCT } \\
\hline & Pediatric & Adults & Pediatric & Adults \\
\hline Salivary Glands & $281.55 \pm 59.68$ & $318.47 \pm 68.92$ & $1770 \pm 8.53$ & $2950.81 \pm 299.34$ \\
\hline Oral Mucosa & $213.26 \pm 56.15$ & $231.6 \pm 67.18$ & $908.41 \pm 11.9$ & $1470.26 \pm 119.55$ \\
\hline Extrathoracic Region & $43.56 \pm 14.41$ & $38.96 \pm 11.32$ & $134.38 \pm 34.52$ & $132.06 \pm 38.40$ \\
\hline Thyroid & $79.13 \pm 15.51$ & $32.61 \pm 10.09$ & $133.5 \pm 18.26$ & $369.03 \pm 31.96$ \\
\hline Skeleton & $54.61 \pm 26.37$ & $45.23 \pm 12.99$ & $110.2 \pm 17.14$ & $387.2 \pm 31.3$ \\
\hline Lymphatic Nodes & $45.04 \pm 18.88$ & $44.97 \pm 12.86$ & $357.99 \pm 34.48$ & $423.9 \pm 39.5$ \\
\hline Brain & $17.8 \pm 9.09$ & $14.79 \pm 4.69$ & $125.6 \pm 24.56$ & $139.7 \pm 34.7$ \\
\hline Skin & $15.91 \pm 7.64$ & $14.13 \pm 3.96$ & $87.1 \pm 17.70$ & $121.1 \pm 19.9$ \\
\hline Red Bone Marrow & $11.91 \pm 5.91$ & $1.43 \pm 0.84$ & $25.4 \pm 4.26$ & $9.66 \pm 3.95$ \\
\hline Muscle & $9.76 \pm 4.76$ & $6.29 \pm 1.8$ & $12.3 \pm 2.49$ & $59.9 \pm 5.44$ \\
\hline Thymus & $3.82 \pm 1.92$ & $0.469 \pm 0.13$ & $5.54 \pm 1.05$ & $9.96 \pm 2.95$ \\
\hline Lung & $2.25 \pm 1.15$ & $1.07 \pm 0.34$ & $5.61 \pm 1.78$ & $11.65 \pm 1.91$ \\
\hline Osophagus & $2.07 \pm 1.12$ & $0.802 \pm 0.28$ & $17.65 \pm 4.43$ & $9.19 \pm 3.62$ \\
\hline Heart & $0.558 \pm 0.30$ & $0.141 \pm 0.060$ & $1.17 \pm 0.25$ & $2.07 \pm 0.127$ \\
\hline Pancreas & $0.258 \pm 0.16$ & $0.0062 \pm 0.0037$ & $1.55 \pm 1.02$ & $0.043 \pm 0.025$ \\
\hline Liver & $0.216 \pm 0.124$ & $0.092 \pm 0.03$ & $0.25 \pm 0.04$ & $0.83 \pm 0.02$ \\
\hline Breast & $0.17 \pm 0.06$ & $0.27 \pm 0.11$ & 0 & $1.94 \pm 0.35$ \\
\hline Adrenals & $0.123 \pm 0.0146$ & 0 & $0.98 \pm 0.10$ & $0.25 \pm 0.08$ \\
\hline Spleen & $0.095 \pm 0.035$ & $0.0021 \pm 0.0013$ & $0.31 \pm 0.09$ & $0.78 \pm 0.67$ \\
\hline Stomach & $0.094 \pm 0.058$ & $0.0035 \pm 0.0042$ & $0.05 \pm 0.003$ & $0.1 \pm 0.1$ \\
\hline Gall Bladder & $0.076 \pm 0.049$ & 0 & 0 & $0.12 \pm 0.17$ \\
\hline Kidneys & $0.053 \pm 0.036$ & $0.0015 \pm 0.0035$ & $0.35 \pm 0.20$ & $0.08 \pm 0.00$ \\
\hline Colon & $0.0097 \pm 0.0066$ & $0.0003 \pm 0.0007$ & $0.044 \pm 0.01$ & $0.01 \pm 0.01$ \\
\hline Small Intestine & $0.0047 \pm 0.0033$ & $0.0011 \pm 0.0006$ & $0.04 \pm 0.002$ & $0.06 \pm 0.003$ \\
\hline Effective dose ( $\mu S v)$ & $12.4 \pm 4.13$ & $10.51 \pm 3.04$ & $17.3 \pm 5.17$ & $9.41 \pm 2.94$ \\
\hline
\end{tabular}

\section{Estimating the REID values}

Figures 1-3 show the mean values of REID with regard to the panoramic and CBCT radiographies from male and female patients in the two groups (per ten million). Following the figures, the mean $( \pm$ SD) REID values in CBCT are $35.6 \pm 5.2$ and $29.01 \pm 1.8$ for females and males, respectively, in the pediatric group, and are $31.1 \pm 2$. 2 and $25.71 \pm 2.02$ in the adult group for all cancers. These values for panoramic radiography are $10.2 \pm 1.2$ and $6.61 \pm 1.2$ for women and men, respectively, in the pediatric group, and are $5.3 \pm 1.06$ and $3.01 \pm 1.12$ in the adult group, for all cancers. There was a remarkable increase in REID risk in pediatrics compared to the adults $(\mathrm{p}<0.05)$, female versus male patients in panoramic radiography $(\mathrm{p}<0.05)$, and also CBCT compared to panoramic $(p<0.01)$. All in all, REID values in pediatric, female, and CBCT were remarkably higher compared to the adult, male, and panoramic radiography.

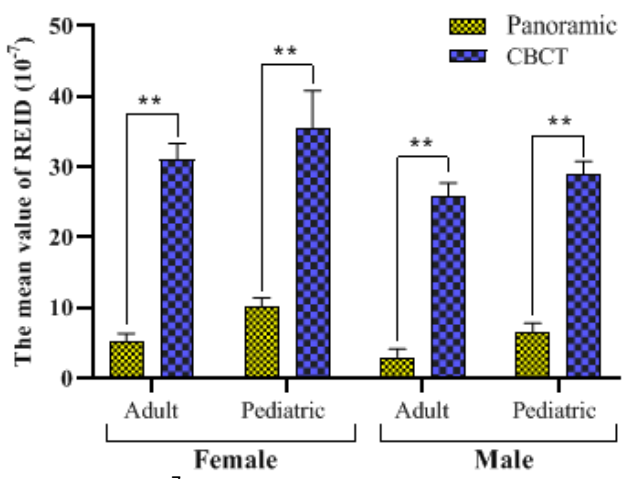

Figure 1. REID $\left(10^{-7}\right)$ for adult and pediatric patients in both genders as function of examinations (CBCT and panoramic). Error bars indicate the standard deviation. ${ }^{* *}$ significant difference between the groups at $\mathrm{P}<0.01$. 


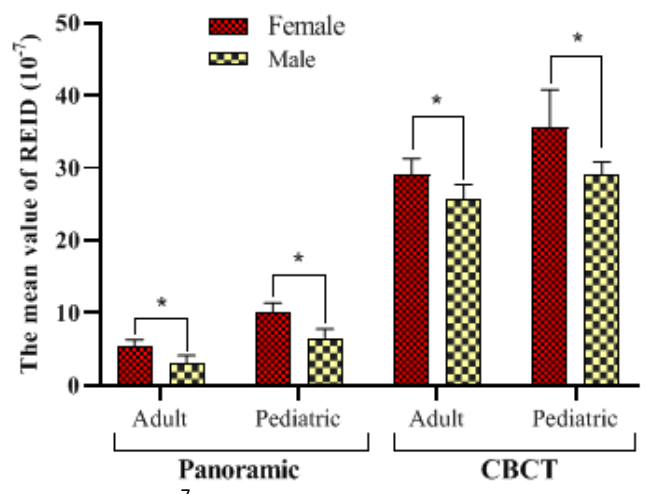

Figure 2. REID $\left(10^{-7}\right)$ for adult and pediatric patients in both CBCT and panoramic examinations as function of genders (male and female). Error bars indicate the standard deviation.

*significant difference between the groups at $\mathrm{P}<0.05$.

\section{Estimating the cancer risks}

Table 6 depicts the cancer risk values (per ten thousand) of the brain, thyroid, all solids, and all cancers for both genders in CBCT and panoramic examinations. The mean cancer risk value for the brain was $17.34 \pm 0.99$ and $2.33 \pm 1.12$ for CBCT and panoramic, respectively. Also, this number for thyroid was obtained at $0.77 \pm 0.21$ and $0.34 \pm 0.17$. For all solids and

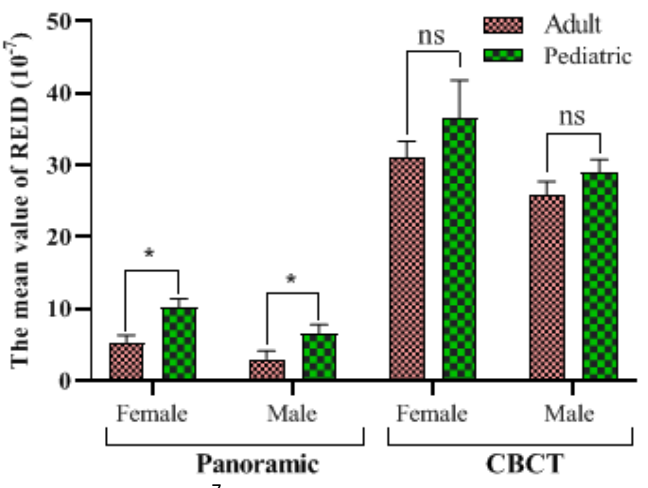

Figure 3. REID $\left(10^{-7}\right)$ for male and female patients in both CBCT and panoramic examinations as function of ages (adult and pediatric). Error bars indicate the standard deviation. *significant difference between the groups at $P<0.05$. nsno significant difference between the groups.

cancers, the mean value of cancer lifetime risk was $18.82 \pm 1.55$ and $18.87 \pm 0.35$ for CBCT, in that order, and it was $2.88 \pm 1.38$ and $2.89 \pm 1.39$ for panoramic radiographs. It is notable that for all four cancer risks there was a significant difference between CBCT and panoramic examinations. In table 7 , more details of p-values have been demonstrated.

Table 6. The mean $( \pm S D$ ) of cancer risk values (per 10,000) for brain, thyroid, all solids, and all cancers for adult and pediatric patients due to panoramic radiography and CBCT.

\begin{tabular}{|c|c|c|c|c|c|}
\hline \multicolumn{2}{|c}{ Organ } & & Bifetime cancer incidence risk & \multirow{2}{*}{ All cancer } \\
\hline \multirow{4}{*}{ Modality } & & Brain & Thyroid & All solids & \\
\hline & Adults & $6.55 \pm 1.63$ & $0.46 \pm 0.05$ & $7.85 \pm 2.73$ & $7.92 \pm 2.80$ \\
\cline { 2 - 6 } & Male & $6.55 \pm 1.63$ & $0.16 \pm 0.04$ & $5.89 \pm 2.05$ & $5.91 \pm 2.18$ \\
\cline { 2 - 6 } & Female & $6.55 \pm 1.63$ & $0.75 \pm 0.08$ & $9.81 \pm 3.41$ & $9.88 \pm 3.39$ \\
\cline { 2 - 6 } & Children & $28.13 \pm 0.35$ & $1.08 \pm 0.22$ & $29.79 \pm 2.37$ & $29.82 \pm 1.91$ \\
\cline { 2 - 6 } & Male & $28.13 \pm 0.35$ & $0.33 \pm 0.09$ & $20.50 \pm 2.25$ & $21.25 \pm 1.36$ \\
\cline { 2 - 6 } & Female & $28.13 \pm 0.35$ & $1.82 \pm 0.31$ & $37.96 \pm 2.48$ & $38.47 \pm 2.46$ \\
\cline { 2 - 6 } & All & $17.34 \pm 0.99$ & $0.77 \pm 0.21$ & $18.82 \pm 1.55$ & $18.87 \pm 0.35$ \\
\cline { 2 - 6 } & Male & $17.34 \pm 0.99$ & $0.24 \pm 0.07$ & $13.19 \pm 1.17$ & $13.79 \pm 1.77$ \\
\cline { 2 - 6 } & Female & $17.34 \pm 0.99$ & $1.28 \pm 0.34$ & $28.88 \pm 2.95$ & $29.42 \pm 2.92$ \\
\hline & Adults & $0.69 \pm 0.22$ & $0.04 \pm 0.01$ & $0.83 \pm 0.26$ & $0.84 \pm 0.26$ \\
\cline { 2 - 6 } & Male & $0.69 \pm 0.22$ & $0.01 \pm 0.00$ & $0.62 \pm 0.19$ & $0.65 \pm 0.20$ \\
\cline { 2 - 6 } & Female & $0.69 \pm 0.22$ & $0.07 \pm 0.02$ & $1.04 \pm 0.32$ & $1.08 \pm 0.31$ \\
\cline { 2 - 6 } & Children & $3.98 \pm 2.04$ & $0.64 \pm 0.33$ & $4.93 \pm 1.51$ & $4.95 \pm 2.52$ \\
\cline { 2 - 6 } & Male & $3.98 \pm 2.04$ & $0.19 \pm 0.1$ & $3.40 \pm 1.73$ & $3.51 \pm 1.79$ \\
\cline { 2 - 6 } & Female & $3.98 \pm 2.04$ & $1.08 \pm 0.56$ & $6.45 \pm 1.64$ & $6.58 \pm 3.25$ \\
\cline { 2 - 6 } & All & $2.33 \pm 1.12$ & $0.34 \pm 0.17$ & $2.88 \pm 1.38$ & $2.89 \pm 1.39$ \\
\cline { 2 - 6 } & Male & $2.33 \pm 1.12$ & $0.1 \pm 0.05$ & $2.01 \pm 0.96$ & $2.08 \pm 1.00$ \\
\cline { 2 - 6 } & Female & $2.33 \pm 1.12$ & $0.57 \pm 0.39$ & $3.75 \pm 1.83$ & $3.95 \pm 1.78$ \\
\hline
\end{tabular}


Table 7. P-values for brain, thyroid, all solids, and cancers for both genders, ages, and radiography systems.

\begin{tabular}{|c|c|c|c|c|c|c|}
\hline \multicolumn{2}{|l|}{ Modality } & \multicolumn{2}{|c|}{ CBCT } & \multicolumn{3}{|c|}{ Panoramic } \\
\hline Organs $\quad$ Comparisons & & $\begin{array}{c}\text { Male vs. } \\
\text { female }\end{array}$ & $\begin{array}{l}\text { Adult vs. } \\
\text { children }\end{array}$ & $\begin{array}{c}\text { Male vs. } \\
\text { female }\end{array}$ & $\begin{array}{l}\text { Adult vs. } \\
\text { children }\end{array}$ & $\begin{array}{c}\text { CBCT vs. } \\
\text { panoramic }\end{array}$ \\
\hline Brain & \multirow{4}{*}{ P-value } & 0.1 & 0.01 & 0.1 & 0.01 & 0.001 \\
\hline Thyroid & & 0.01 & 0.03 & 0.02 & 0.01 & 0.04 \\
\hline All solids & & 0.06 & 0.02 & 0.07 & 0.04 & 0.001 \\
\hline All cancers & & 0.06 & 0.02 & 0.06 & 0.03 & 0.001 \\
\hline
\end{tabular}

\section{DISCUSSION}

In the present study, we aimed to calculate the input dose, organ dose, effective dose, cancer risk, and REID values in CBCT and panoramic radiographies in two different age groups for both male and female groups. Also, we intended to compare the absorbed doses and cancer risk values between each device, based on values assessed for adult and pediatric groups.

Results indicated that the DAP values increased with the rise in patient age in almost all examinations. The mean value of DAP for the adult patient undergoing panoramic radiography was $91.22 \mathrm{mGy} . \mathrm{cm}^{2}$ which is in line with Poppe et al. (20), Hart et al. (21), and Chaparian et al. (16) studies, but it was lower than the results of Choi et al. (22) study. The mean DAP value for CBCT was $943 \mathrm{mGy}_{\mathrm{cm}}^{2}$, which is higher considerably compared to the panoramic radiography. The results of our study were consistent with those of the other relevant studies $(6,23,24)$. The reason for some discrepancies with the other studies can be attributed to the use of different X-ray machines and setting parameters for each X-ray examination.

Our findings demonstrated that the effective dose decreased with an increase in age which is similar to the other studies results like Chaparian et al. (16) and Zenone etal. (25). The reason can be due to the involvement of more organs in younger groups in the same field size used for older patients. As shown in table 5, the highest organ absorbed dose was found in the salivary glands and then oral mocusa in both CBCT and panoramic examinations. In general, the absorbed dose value is higher significantly in CBCT in comparison with panoramic because of the higher X-ray setting factors and the different geometry of CBCT $(1,10,23,26)$.

The REID values in the pediatric group were approximately double those in the adult almost in all cancers. Children have a larger proportion of dividing cells due to their growing periods, therefore, they are inherently more vulnerable to radiation. In addition, as mentioned in the above paragraph, the adjacent organs in children receive larger doses of scatter radiation than adults due to the smaller body size (15). The results show a high degree of agreement with Jih -Kuei et al. (15) research. Horner et al. (27) investigated the REID value for adults during panoramic radiography and it was between 2 to 9 (per ten million) which is relatively consistent with the results of present study (3 to 5). The discrepancy between the studies can be possiblly because of different devices and radiation conditions. Another reason might be the use of different methods for obtaining the cancer risk so that the effective dose was simply multiplied by constant coefficients in some studies, while the risk estimation in our study was applied based on the BEIR VII model (19). In general, the highest change in the REID values was found in female patients in the two types of dental X-ray and this can be related to the breast organ as a sensitive tissue (28).

The mean cancer risk value in CBCT was higher in panoramic examination considerably (table 7) which is related to the higher radiation parameters. In Pauwels et al. (29) study the cancer lifetime risk for CBCT was 0.0027 for adults and 0.0098 for pediatric patients per ten thousand which shows that it is 3.5 times higher for pediatric, approximately. According to the findings of the present study, the mean cancer risk value for children is almost 4 times higher 
in all mentioned cancers.

Regarding the higher radiation and cancer risk in CBCT, it should be justified in the examinations which provide new information compared to panoramic radiography $(29,30)$.

In the current work, we measured the absorbed dose and cancer-induced risks using only the DAP-meter. Furthermore, we did not investigate the relationship between radiation dose and field of view, which can provide various anatomic coverage areas of the radiosensitive organs during the radiographic examinations. Thus, for future research, it is suggested that other dosimetric tools such as thermoluminescent and radiochromic film in different dental radiography systems should be used at various fields of view and the results be compared with DAP-meter.

\section{CONCLUSION}

Following the explanations given in this study, the total REID and cancer risk values in pediatric, female, and CBCT are higher, therefore, it is notable that clinicians should request the dental examinations by considering their risks and benefits during treatment procedures.

\section{ACKNOWLEDGEMENTS}

This work was approved by Shahid Sadoughi University of Medical Sciences (Yazd, Iran). The authors would like to thank the radiography centers for their collaboration in this project.

Conflicts of interest: Declared none.

\section{REFERENCES}

1. Granlund C, Thilander-Klang A, Ylhan B, Lofthag-Hansen S, Ekestubbe A (2016) Absorbed organ and effective doses from digital intra-oral and panoramic radiography applying the ICRP 103 recommendations for effective dose estimations. Brit J Radiol, 89(1066): 20151052.
2. Haney E, Gansky SA, Lee JS, Johnson E, Maki K, Miller AJ, et al. (2010) Comparative analysis of traditional radiographs and cone-beam computed tomography volumetric images in the diagnosis and treatment planning of maxillary impacted canines. Am J Orthod Dentofac, 137(5): 590 $-597$.

3. Farman AG and Scarfe WC (2009) The basics of maxillofacial cone beam computed tomography. Seminars in Orthodontics, 15(1): 2-13.

4. Cho P, Kim Y, Jang H, Han E (2018) Radiation safety behavior model for dental hygiene departments of universities in South Korea. Int J Radiat Res, 16(1): 95-106.

5. Akyalcin S, English JD, Abramovitch KM, Rong XJ (2013) Measurement of skin dose from cone-beam computed tomography imaging. Head Face Med, 9(1): 28.

6. Suomalainen A, Esmaeili EP, Robinson S (2015) Dentomaxillofacial imaging with panoramic views and cone beam CT. Insights Imaging, 6(1): 1-16.

7. Li G (2013) Patient radiation dose and protection from cone-beam computed tomography. Imaging Sci Dent, $\mathbf{4 3}$ (2): 63-69.

8. Granlund C, Thilander-Klang A, Ylhan B, Lofthag-Hansen S, Ekestubbe A (2016) Absorbed organ and effective doses from digital intra-oral and panoramic radiography applying the ICRP 103 recommendations for effective dose estimations. Brit J Radiol, 89(1066): 20151052.

9. Eskandarlou A, Ghazi KSK, Mahdizadeh A (2010) Radiation protection principles observance in Iranian dental schools. Int J Radiat Res, 8(1): 51-57.

10. Heiden KR, Rocha ASPSd, Filipov D, Salazar CB, Fernandes $\hat{A}$, Westphalen $\mathrm{FH}$, et al. (2018) Absorbed doses in salivary and thyroid glands from panoramic radiography and cone beam computed tomography. Biomed. Eng, 34(1): 31-36.

11. Hodolli G, Kadiri S, Nafezi G, Bahtijari M,Syla N (2019) Diagnostic reference levels at intraoral and dental panoramic examinations. Int J Radiat Res, 17(1): 147-150.

12. Aps J (2013) Theoretical assessment of the thyroid gland's radiation dose from radiographs taken in dento-alveolar trauma in pediatric patients. IJPNC, 1(1): 104.

13. Souza EM, Lima MA, Kelecom A, Correa SC, Silva AX, Brito A (2008) Dose and risk evaluation to the thyroid gland in intra-oral dental radiology. Argentina. Report? seminar? date? page?

14. ICRP (1990) ICRP publication 60: 1990 recommendations of the International Commission on Radiological Protection.

15. Yeh JK and Chen $\mathrm{CH}$ (2018) Estimated radiation risk of cancer from dental cone-beam computed tomography imaging in orthodontics patients. BMC Oral Health, 18(1): 131.

16. Chaparian A, Dehghanzade $F$ (2017) Evaluation of radiation-induced cancer risk to patients undergoing intra-oral and panoramic dental radiographies using experimental measurements and Monte Carlo calculations. Int J Radiat Res, 15(2): 197.

17. Deng J, Ming X, Zhang Y, Zhou L, Zhang Y,Wu H (2014) CT Gently: Personalizing CT and CBCT Imaging for the Children. SAJ Cancer Sci, 1(1): 101.

Int. J. Radiat. Res., Vol. 18 No. 4, October 2020 
18. Valentin J (2007) International Commission on Radiological Protection., 2007. The 2007 recommendations of the International Commission on Radiological Protection. Annals of the ICRP 103.

19. Council NR (2006) Health risks from exposure to low levels of ionizing radiation: BEIR VII phase 2. National Academies Press, Vol. 7. Place of publication?

20. Poppe B, Looe H, Pfaffenberger A, Chofor N, Eenboom F, Sering $M$, et al. (2007) Dose-area product measurements in panoramic dental radiology. Radiat Prot Dosim, 123(1): 131-134.

21. Hart D, Hillier M, Wall B (2009) National reference doses for common radiographic, fluoroscopic and dental X-ray examinations in the UK. Brit J Radiol, 82(973): 1-12.

22. Choi E (2014) Phantom dosimetry of i-CAT CBCT and i-CAT panoramic radiographs in pediatric patients. University of British Columbia. Report? seminar? date? page?

23. Kadesjö N, Lynds R, Nilsson M, Shi X-Q (2018) Radiation dose from $\mathrm{X}$-ray examinations of impacted canines: cone beam CT vs two-dimensional imaging. Dentomaxillofac Radiol, 47(3): 20170305.

24. Shin H, Nam K, Park H, Choi H, Kim H, Park C (2014) Effective doses from panoramic radiography and $\mathrm{CBCT}$ (cone beam CT) using dose area product (DAP) in dentistry. Dentomaxillofac RAD, 43(5): 20130439.
25. Zenone F, Aimonetto S, Catuzzo P, Peruzzo Cornetto A, Marchisio P, Natrella M, et al. (2012) Effective dose delivered by conventional radiology to Aosta Valley population between 2002 and 2009. Brit J Radiol, 85(1015): e330e338.

26. Gijbels F, Jacobs R, Bogaerts R, Debaveye D, Verlinden S, Sanderink $G$ (2005) Dosimetry of digital panoramic imaging. Part I: Patient exposure. Dentomaxillofac RAD, 34(3): 145-149.

27. Horner K, Rushton V, Tsiklakis K, Hirschmann P, van der Stelt P, Glenny A, et al. (2004) European guidelines on radiation protection in dental radiology; the safe use of radiographs in dental practice. European Commission, Directorate-General for Energy and Transport. the University of Amsterdam: Brussel, Belgium: EU. Vol. 425. Report? seminar? date? page?

28. Howell RM and Kry SF (2010) Radiation dose and breast cancer risk in the childhood cancer survivor study. Breast Dis, 21(3): 270-271.

29. Pauwels $R$, Cockmartin L, Ivanauskaité $D$, Urbonienè $A$, Gavala S, Donta C, et al. (2014) Estimating cancer risk from dental cone-beam CT exposures based on skin dosimetry. PHYS MED BIOL, 59(14): 3877.

30. Jaju PP and Jaju SP (2015) Cone-beam computed tomography: time to move from ALARA to ALADA. Imaging Sci Dent, 45(4): 263-265. 
